\title{
The PA4204 gene encodes a periplasmic gluconolactonase (PpgL) which is important for fitness of Pseudomonas aeruginosa
}

\begin{abstract}
Correspondence
Pierre Cornelis

pcornel@vub.ac.be
\end{abstract}

Received 14 March 2008

Revised 6 June 2008

Accepted 16 June 2008

\author{
Saeed Tarighi, ${ }^{1} \dagger$ Oing Wei, ${ }^{1} \dagger$ Miguel Cámara, ${ }^{2}$ Paul Williams, ${ }^{2}$ \\ Matthew P. Fletcher, ${ }^{2}$ Tommi Kajander $^{3}$ and Pierre Cornelis ${ }^{1}$
}
${ }^{1}$ Laboratory of Microbial Interactions, Department of Molecular and Cellular Interactions, Flanders Institute of Biotechnology (VIB), Vrije Universiteit Brussel, Pleinlaan 2, 1050 Brussels, Belgium
${ }^{2}$ Institute of Infection, Immunity and Inflammation, Centre for Biomolecular Sciences, University Park, University of Nottingham, Nottingham NG7 2RD, UK
${ }^{3}$ Macromolecular X-ray Crystallography, Research Program in Structural Biology and Biophysics, Institute of Biotechnology, University of Helsinki, Helsinki, Finland

In Pseudomonas aeruginosa, the PA4204 gene encodes a protein with a signal peptide and a COG2706 domain of the type present in 3-carboxy-cis,cis-muconate lactonizing enzymes. A molecular model based on the structure of the Escherichia coli YbhE phosphogluconate lactonizing enzyme shows that the enzyme has a beta-propeller ('doughnut') structure and a central active site comprising one histidine, one glutamic acid and two arginines. Inactivation of the $P$. aeruginosa PA4204 gene had profound phenotypic effects, resulting in slowly growing small colonies which frequently gave rise to larger colonies. The small colonies did not produce pyocyanin, produced reduced amounts of $N$-acylhomoserine lactones, and had extremely low levels of 2-alkyl-4-quinolones (AQs), while the larger colonies produced pyocyanin and higher amounts of AQs, including the pseudomonas quinolone signal (PQS), compared with the wildtype strain. Mutagenesis of His 182 in PA4204 resulted in the inability of this protein to restore pyocyanin production in the PA4204 isogenic mutant, suggesting that this enzyme may share an active site with other lactonizing enzymes. The protein with signal peptide was expressed as a His fusion in E. coli and purified. Two forms were observed, suggesting that the protein is translocated. The purified enzyme cleaved (S)-5-oxo-2-tetrahydrofurancarboxylic acid and Dglucono- $\delta$-lactone, demonstrating lactonase activity. Decreased expression of the cytoplasmic phosphogluconolactonase gene $(\mathrm{pgl})$ was observed in the small-colony mutant, and the mutant could not grow in the presence of mannitol or gluconate, suggesting functions in the detoxification of a gluconolactone and in sugar metabolism.

\section{INTRODUCTION}

Fluorescent pseudomonads are ubiquitous Gram-negative $\gamma$-Proteobacteria, and can adapt to diverse ecological niches (Goldberg, 2000). Several genomes of fluorescent pseudomonads have been or are being sequenced, reflecting their broad interest to the scientific community

†These authors contributed equally to this work.

Abbreviations: $\mathrm{AHL}$, acylhomoserinelactone; $\mathrm{AQ}, 2$ 2-alkyl-4-quinolone; CMLE, carboxymuconolactonase; ED, Entner-Doudoroff; LC-MS, liquid chromatography-mass spectrometry; PGL, phosphogluconolactonase; PQS, pseudomonas quinolone signal; OS, quorum sensing.

A supplementary figure showing the alignment of the product of PA4204 with YbhE of E. coli, the L- $\alpha$-hydroxyglutaric acid gammalactonase of Pectobacterium (Erwinia) cyprepedii, and the CMLE from Neurospora crassa is available with the online version of this paper. (http://www.pseudomonas.com). However, a large proportion of the genes encode proteins of unknown function. This is the case for a gene upstream of mexGHI-opmD, PA4204, which encodes a putative periplasmic protein, with a COG2706 domain found in carboxymuconolactonases (CMLEs). The product of PA4204 also has similarity to 6-phosphogluconolactonases (PGLs). PGLs have an important function in the oxidative branch of the pentose phosphate pathway, since they convert $\delta$-6-phosphogluconolactone, the product of the glucose 6-phosphate dehydrogenation, to 6-phosphogluconate, which can enter the Entner-Doudoroff (ED) pathway (Kupor \& Fraenkel, 1969; Miclet et al., 2001; Thomason et al., 2004; Zimenkov et al., 2005). In the absence of PGL, $\delta$-6-phosphogluconolactone can spontaneously isomerize to $\gamma$-6-phosphogluconolactone, which is toxic (Miclet et al., 2001; Zimenkov 
et al., 2005). Two kinds of 6-phosphogluconolactonases, which are not structurally similar, have been described: the Escherichia coli PGL type, and the Pseudomonas type (Hager et al., 2000). Interestingly, the PGL of Pseudomonas aeruginosa is a cytoplasmic enzyme encoded by another gene, PA3182, while PA4204 is similar to YbhE, the E. coli PGL (Thomason et al., 2004; Zimenkov et al., 2005). PGLs therefore have not only a catalytic function, but also prevent the accumulation of toxic, non-degradable metabolites, having an important 'house-cleaning' function (Galperin et al., 2006). In their article, Galperin et al. (2006) indeed describe PA4204 as a possible 6-phosphogluconolactonase with such a house-cleaning function. However, PGLs are normally cytoplasmic, while the product of PA4204 is probably localized in the periplasm. Mochizuki $(2003,2006)$ identified a similar enzyme, also with a predicted periplasmic location, in Erwinia cypripedii 314B (now Pectobacterium cypripedii) with a lactonase activity specific for (S)-5-oxo-2-tetrahydrofurancarboxylic acid, which converts this molecule to L- $\alpha$-hydroxyglutaric acid. Orthologues of the PA4204 gene are also present in many proteobacteria and in all pseudomonads, but not in the same genomic context as in $P$. aeruginosa. In this bacterium, the presence of this gene close to the mexGHIopmD locus also raises the question of a possible link with quorum sensing (QS). We have previously shown that mutants in the mexI and $o p m D$ genes produce drastically reduced amounts of the QS signal molecule PQS (pseudomonas quinolone signal) and the phenazine pyocyanin (Diggle et al., 2006; Dietrich et al., 2006; Aendekerk et al., 2002, 2005). We decided to inactivate PA4204 in order to determine whether this gene also influences the production of QS signal molecules. We demonstrate here (i) that the PA4204 gene encodes a periplasmic enzyme with a $\beta$-propeller fold; (ii) that it has the same lactonase activity as the enzyme described by Mochizuki $(2003,2006)$ and that it also cleaves D-glucono$\delta$-lactone; (iii) that it is important for the fitness of the bacterium and for growth on gluconate, 2-ketogluconate and mannitol; (iv) that in its absence the expression of the cytoplasmic PGL is decreased; and (v) that it affects the production of QS signal molecules, especially the $\mathrm{N}$ acylhomoserinelactones (AHLs) and the alkyl-quinolones, including PQS.

\section{METHODS}

Bacterial strains, plasmids, and growth conditions. The bacterial strains and plasmids that were used in this study are listed in Table 1. E. coli DH5 $\alpha$ and E. coli S17-1 $\lambda$ pir were used for cloning and conjugation experiments. $P$. aeruginosa strains were grown at $37^{\circ} \mathrm{C}$ in Luria-Bertani (LB) broth or on LB agar plates, iron-poor casamino acids (CAA) medium (Difco Laboratories), Pseudomonas agar medium (Difco Laboratories) or King's B medium (King et al., 1954). The following concentrations of antibiotics were used for $P$. aeruginosa: gentamicin, $100 \mu \mathrm{g} \mathrm{ml}^{-1}$; tetracycline, $200 \mu \mathrm{g} \mathrm{ml}{ }^{-1}$; chloramphenicol, $350 \mu \mathrm{g} \mathrm{ml}^{-1}$. Growth was also followed in minimal succinate medium (Meyer \& Abdallah, 1978) containing a limiting amount of succinate $(2 \mathrm{mM})$ and $20 \mathrm{mM}$ of one of the following carbon sources: phenol, succinate, protocatechuate, cis,cis-muconate, catechol, glucose, fructose, gluconate, 2-ketogluconate or mannitol. Because of the appearance of spontaneous pseudo-revertants (see Results), growth was monitored in triplicate and the curves were considered valid for the PA4204 mutant only when growth started at the same moment in the three cultures. Earlier onset of growth in one of the cultures was considered to be the consequence of the appearance of a revertant, and the corresponding data were therefore not taken into account.

DNA manipulation and in silico analysis of the PA4204 gene. Plasmid DNA was isolated from E. coli using the QIAprep Spin Miniprep kit (Qiagen). All restriction enzymes were purchased from Fermentas and used according to the manufacturer's instructions. DNA subcloning, transformations and agarose gel electrophoresis were done as described elsewhere (Sambrook et al., 1989). Similarity searches were performed with the BLAST program (Altschul et al., 1997) and amino acid sequence alignment was performed using CLUstal W (Thompson et al., 1997) or Kalign (Lassmann \& Sonnhammer, 2006).

Strain and plasmid construction. An in-frame and unmarked PA4204 deletion mutant of $P$. aeruginosa PAO1 was constructed using the suicide vector pDM4 (Milton et al., 1996). This vector contains the lethal $s a c B$ gene encoding levansucrase, and recombination of the vector onto the chromosome confers chloramphenicol resistance to the host strain. Approximately $500 \mathrm{bp}$ of upstream and downstream sequences flanking the gene of interest were amplified by PCR with primers PA4204-F and PA4204-R using chromosomal DNA as the template and cloned into pBluescript, resulting in plasmid pBlu4204 (Table 1). These plasmids were used as templates to introduce a deletion by inverse PCR using primers PA4204-UM-F and PA4204UM-R. The resulting PCR product was digested with XmaI and selfligated, resulting in the plasmid pBlu $\Delta 4204$. The PCR product was excised from the vectors and cloned into the pDM4 vector, resulting in $\mathrm{pDM} \Delta 4204$. The pDM4-based deletion allele was mobilized into $P$. aeruginosa and integrated into the chromosome by single crossover using E. coli S17-1 $\lambda$ pir as the delivery strain. Double-crossover events were subsequently selected by growth in the presence of $10 \%$ ( $P$. aeruginosa) sucrose. Deletion mutants were confirmed by both PCR and sequencing.

Cloning of the PA4204 gene. The complete PA4204 gene was amplified by PCR with primers PA-4204-F and PA-4204-R. The $1.5 \mathrm{~kb}$ PCR fragment obtained was digested further with ClaI and BamHI and cloned into the ClaI/BamHI-opened vector pBBR1MCS, resulting in pBBR-4204. This plasmid was used to transform E. coli $\mathrm{DH} 5 \alpha$, and chloramphenicol-resistant colonies were selected. The recombinant plasmid was introduced by electroporation into the PA4204 P. aeruginosa mutant.

Molecular modelling. The PA4204 structure was modelled using the automated FFAS03 fold recognition server (Rychlewski et al., 2000) to generate the starting model using E. coli $\mathrm{YhbE}$ as the template (the YhbE phosphogluconolactonase and CMLE structures gave the highest scores), then manually edited with the molecular graphics program O (Jones et al., 1991) to fix some peptide bonds, and minimized with CNS (Brünger et al., 1998) with conjugate gradient minimization for 100 steps. The structure was then aligned with the Neurospora crassa CMLE structure using $\mathrm{O}$ to analyse for fit of the conserved residues.

Site-directed mutagenesis using a PCR method with mutagenic primers. The $1.5 \mathrm{~kb} \mathrm{ClaI-BamHI}$ fragment containing the entire PA4204 locus was amplified using genomic DNA of $P$. aeruginosa $\mathrm{PAO} 1$ and was used for mutagenesis. Mutations were generated via PCR using Taq polymerase (Qiagen) with mutagenic 
Table 1. Bacterial strains and plasmids used in this study

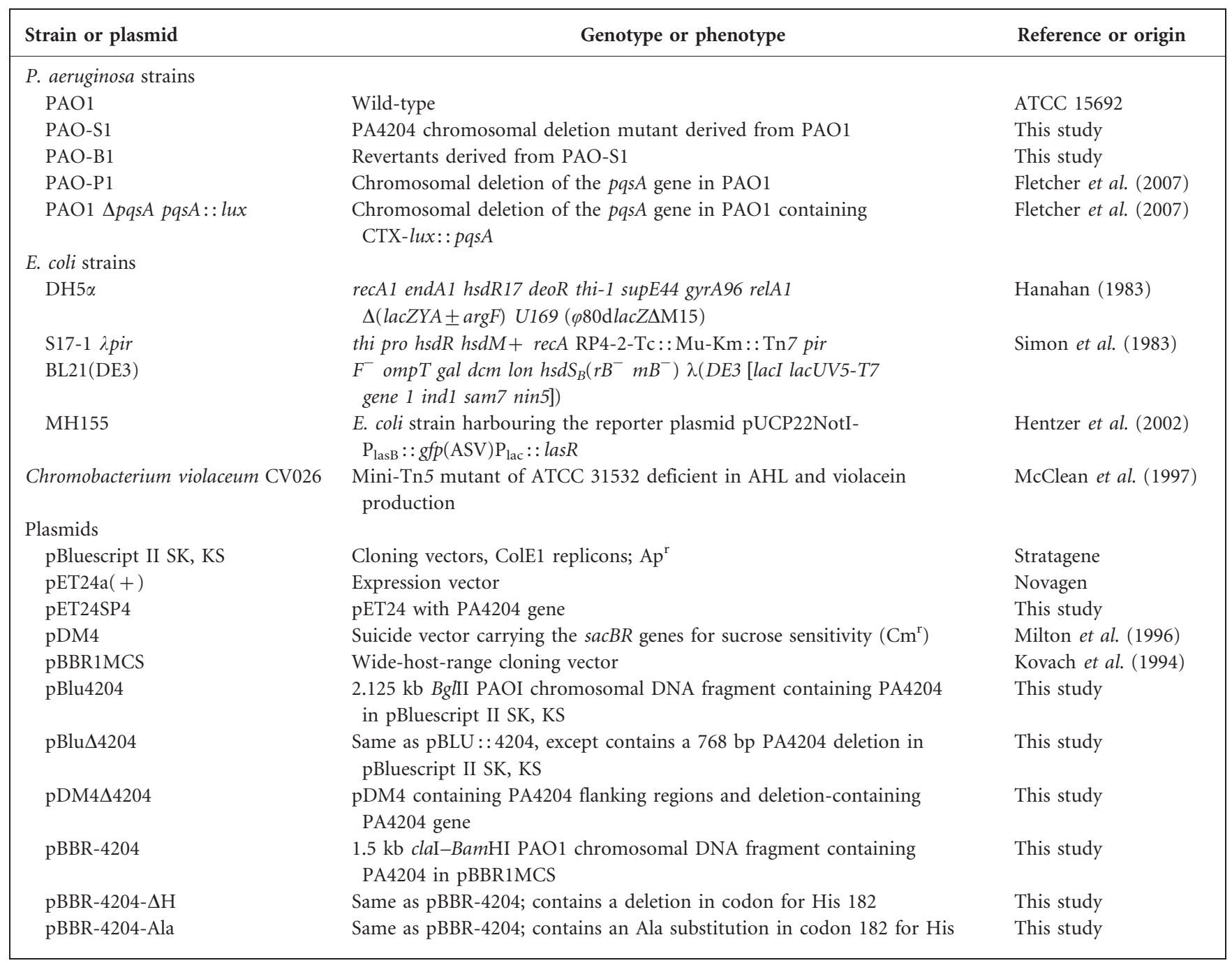

primers PA-PpgL- $\Delta \mathrm{H}-\mathrm{F}, \mathrm{PA}-\mathrm{PpgL}-\Delta \mathrm{H}-\mathrm{R}, \mathrm{PA}-\mathrm{PpgL}-\mathrm{Ala}-\mathrm{F}$ and PAPpgL-Ala-R (in which His 182 was deleted or substituted by Ala by changing the CAC codon to GCG) in combination with primers PAPpgL-F and PA-PpgL-R and the following parameters: 1 min at $94{ }^{\circ} \mathrm{C}$, $1 \mathrm{~min}$ at $58{ }^{\circ} \mathrm{C}$ and $1 \mathrm{~min}$ at $72{ }^{\circ} \mathrm{C}$ for 25 cycles. A final extension of $10 \mathrm{~min}$ at $72{ }^{\circ} \mathrm{C}$ allowed completion of the PCR fragments. To generate the complete $1.5 \mathrm{~kb}$ fragment containing the mutation, a third PCR was performed using Proofstart Polymerase (Qiagen) and the products of the former PCRs as template. Primers PA-PpgL-F and PA-PpgL-R were added after five cycles. The nucleotide change was confirmed by sequencing (Forman et al., 2006). Mutated PCR products were digested with $\mathrm{ClaI}$ and $\mathrm{BamHI}$ and cloned into pBBR1MCS to generate pBBR-4204- $\Delta \mathrm{H}$ and pBBR-4204-Ala. These two plasmids were used to complement the PA4204 mutant.

Pyocyanin production. Pyocyanin was visualized by growing the bacteria in LB medium or on P-agar. Pyocyanin was extracted and quantified from stationary-phase cultures as described elsewhere (Mavrodi et al., 2001). All experiments were done in triplicate.

Liquid chromatography-MS (LC-MS) detection of QS signal molecules. For accurate quantification of AHL and 2-alkyl-4quinolones (AQs), bacterial cultures were grown for $8 \mathrm{~h}$ at $37{ }^{\circ} \mathrm{C}$ and 200 r.p.m. in $30 \mathrm{ml} \mathrm{LB}$. From each culture, $5 \times 5 \mathrm{ml}$ aliquots were removed for quintuplicate solvent extractions. Culture supernatants were filtered through a $0.22 \mu \mathrm{m}$ pore-size filter and QS molecules were extracted with ethyl acetate, whereas pellets were extracted with methanol and then filtered through a $0.22 \mu \mathrm{m}$ pore-size filter. Extracts were dried to completion, resuspended in $1 \mathrm{ml}$ methanol and analysed by reverse-phase HPLC (RP-HPLC) using a Phenomenex Gemini column $(\mathrm{C} 18,5 \mu \mathrm{m}, 250 \times 2.00 \mathrm{~mm})$ coupled with $\mathrm{MS}$. The fragmentation ions of each of the anticipated QS molecules were recorded using Multiple Reaction Monitoring (MRM), as used by Ortori et al. (2007). Error bars on the relevant figures represent $2 \times \operatorname{SEM}(95 \%$ confidence interval $)$.

Cloning, overexpression and purification of PA4204. The complete ORF of PA4204, including part of the signal peptide, was amplified using primers PA4204-SPF (5' GGGAATTCCATATGAGAAGACTGCCCACCCTC 3') and PA4204-R1 (5' CCG $\overline{\text { CTCGAG- }}$ CGGCACCGCCACGAAG 3'). Primer PA4204-SPF contains an NdeI restriction site, while primer PA4204-R1 contains a XhoI restriction site (both underlined). After amplification, the fragment was cloned in the $\mathrm{pET} 24 \mathrm{a}(+)$ vector (Novagen) and the ligation mix was used to transform E. coli $\mathrm{DH} 5 \alpha$, and transformants were selected for their resistance to kanamycin $\left(60 \mu \mathrm{g} \mathrm{ml}^{-1}\right)$. Sequencing of the fragment was performed to check for the absence of mutations that could have been generated during the PCR; for this, primers pET24a $(+)\left(5^{\prime}\right.$ 
CAATTTGTTTTAATAAAGATC 3') and pET3a-reverse2 (5' CCACCGAGTGCACATGAC $3^{\prime}$ ), and pET3a2 (5' GTCATGTGCACTCGGTGG $3^{\prime}$ ) and pET3areverse (5' CCAACTCAGCTTCCTTTCGGGC $3^{\prime}$ ) were used. The recombinant plasmid pET24SP4 was then extracted from E. coli $\mathrm{DH} 5 \alpha$ and used to transform $E$. coli BL21(DE3). Expression of PA4204 in this strain was induced by adding IPTG $(1 \mathrm{mM})$ when the culture reached $\mathrm{OD}_{600} 0.6$ (LB medium). Growth under inducing conditions was done in a $300 \mathrm{ml}$ volume at $30{ }^{\circ} \mathrm{C}$ for different periods of time ( $5 \mathrm{~h}$ to overnight). After centrifugation, the cell pellet was resuspended in $10 \mathrm{ml} 0.9 \%(\mathrm{w} / \mathrm{v})$ cold $\mathrm{NaCl}$ and centrifuged at 7000 r.p.m. for $10 \mathrm{~min}$. The resulting pellet was then resuspended in $6 \mathrm{ml} 20 \mathrm{mM}$ phosphate buffer, $0.5 \mathrm{M}$ $\mathrm{NaCl}, 40 \mathrm{mM}$ imidazole, $\mathrm{pH}$ 7.4. The cells were then broken by sonication in a Vibra Cell sonicator (Fisher Bioblock Scientific) at $20 \%$ of the maximal amplitude for $15 \mathrm{~min}$, followed by centrifugation at 10000 r.p.m. for $10 \mathrm{~min}$ (Sorvall SS34 rotor), and the supernatant was recovered as a total crude protein extract. The total extract $(10 \mathrm{ml})$ was injected into a His-Trap nickel affinity chromatography column $(2 \times 1 \mathrm{~cm})$, and the elution was followed in an AKTA FPLC system. First, the column was washed with buffer A (20 mM phosphate buffer, $0.5 \mathrm{M} \mathrm{NaCl}, 40 \mathrm{mM}$ imidazole, $\mathrm{pH} 7.4$ ) and the His-tagged protein eluted using buffer B (20 mM phosphate buffer, $0.5 \mathrm{M} \mathrm{NaCl}, 500 \mathrm{mM}$ imidazole, $\mathrm{pH}$ 7.4). The fractions were analysed for their purity by SDS-PAGE (12\% gel). The pooled fractions containing the purified proteins were further purified by Superdex 75 gel filtration. The final purified protein peak was then dialysed further overnight against $20 \mathrm{mM}$ PBS, $150 \mathrm{mM} \mathrm{NaCl}$, $\mathrm{pH} 7.2$.

Hydroxyglutaric acid $\gamma$-lactonase (HGL) assay. The L- $\alpha$-hydroxyglutaric acid $\gamma$-lactonase ( $\mathrm{L}-\alpha-\mathrm{HGL}$ ) activity was determined as described elsewhere (Mochizuki, 2003), with modifications. The activity toward (S)-5-oxo-2-tetrahydrofurancarboxylic acid was determined in an assay mixture containing $10 \mathrm{mM}$ substrate, $10 \mathrm{mM}$ phosphate buffer ( $\mathrm{pH} 7.0$ ), and purified enzyme extract. After incubation at $37{ }^{\circ} \mathrm{C}$ for $1-10 \mathrm{~min}$, an aliquot was taken and placed in boiling water for $1 \mathrm{~min}$ to terminate the reaction. After removal of the precipitated protein by centrifugation for $10 \mathrm{~min}$ at 14000 r.p.m. in an Eppendorf benchtop centrifuge 5417C, the resulting hydroxycarboxylic acid was detected by HPLC as described by Mochizuki (2001) using an Inertsil ODS-3 column $(4.6 \times 250 \mathrm{~mm}$; GL Science) at a flow rate of $1.0 \mathrm{ml} \mathrm{min}{ }^{-1}$, monitoring at $210 \mathrm{~nm}$ with $0.1 \%(\mathrm{w} / \mathrm{v}) \mathrm{H}_{3} \mathrm{PO}_{4}$ as an eluent. The negative control was assay mixture without enzyme. Protein concentration was determined by standard Bradford method HPLC (Mochizuki, 2001).

Glucono- $\boldsymbol{\delta}$-lactonase assay. Gluconolactonase activity was determined using the colorimetric assay described by Hucho \& Wallenfels (1972) and D-glucono- $\delta$-lactone as substrate (Sigma). The substrate solution was prepared immediately before the assay. A $10 \mathrm{ml}$ volume of a $0.25 \mathrm{mM}$ p-nitrophenol (Sigma) solution in $10 \mathrm{mM}$ phosphate buffer ( $\mathrm{pH} 7.2)$ was added to $18.5 \mathrm{mg}$ D-glucono- $\delta$-lactone $(10 \mathrm{mM}$ final concentration). After addition of the enzyme $(10 \mu \mathrm{l}, 1.6 \mu \mathrm{g})$ to $0.99 \mathrm{ml}$ of the mix in the cuvette, the $A_{405}$ was measured at $24{ }^{\circ} \mathrm{C}$. Opening of the lactone ring causes acidification of the medium and a decrease in the absorbance of $p$-nitrophenol.

RT-PCR analysis of $\mathbf{p g l}$ gene expression. Bacterial RNA was extracted by using the High Pure RNA Isolation kit (Roche). Firststrand cDNA was synthesized by using the First-strand cDNA Synthesis kit (Amersham Biosciences). PCR was performed with the following cycling parameters: $95{ }^{\circ} \mathrm{C}$ for 2 min followed by 30 cycles of $94{ }^{\circ} \mathrm{C}$ for $30 \mathrm{~s}, 55{ }^{\circ} \mathrm{C}$ for $30 \mathrm{~s}$, and $72{ }^{\circ} \mathrm{C}$ for $60 \mathrm{~s}$, followed by $72{ }^{\circ} \mathrm{C}$ for $10 \mathrm{~min}$. The oprL gene was used as a normalizer in this test (Aendekerk et al., 2005). Amplification products were electrophoresed on $0.8 \%$ agarose gels (with an $8 \mu$ l loading volume).

\section{RESULTS}

\section{In silico analysis of the PA4204 gene}

In $P$. aeruginosa, PA4204 is located between PA4203, encoding a putative LysR regulator (upstream, same orientation), and the mexGHI-opmD pump genes (downstream, same orientation) (Fig. 1a). The product of PA4204 has 388 amino acids, contains a type I signal peptide with no predicted transmembrane domains and is predicted to have a periplasmic location (Lewenza et al., 2005). A search of the Pseudomonas genome databases revealed the presence of PA4204 homologues in Pseudomonas syringae B728a (Psyr_1712, 51.62\% identity at amino acid level), Pseudomonas fluorescens Pf5 (PFL_3276, 53.66\% identity) and Pseudomonas putida KT2440 (PP2021, 50.5\% identity), although the genetic context in these organisms was very different to that found in $P$. aeruginosa PAO1 (data not shown).

The predicted PA4204 protein shows similarity with the E. coli 6-phosphogluconolactonase YbhE [28\% identity and $46 \%$ similarity $\left(\mathrm{E}=3.6 \times 10^{-19}\right)$ (gi 16128735)], to the periplasmic lactonase from Pectobacterium (Erwinia) cypripedii $(21.5 \%$ identity, $36 \%$ similarity; gi 83016742 ; Mochizuki, 2003, 2006) and to the CMLE (18\% identity, $35 \%$ similarity; P38677) from Neurospora crassa, the crystal structure of which has been determined (Mazur et al., 1994; Kajander et al., 2002). Furthermore, the PA4204 protein has the COG2706 domain found in CMLE, but the high similarity to E. coli YbhE suggests that it could also be a 6-phosphogluconolactonase. The alignment of the amino acid sequences of these proteins, shown in Supplementary Fig. S1, reveals some conserved residues, including those found to be in the active site of YbhE and the N. crassa CMLE (His 182, corresponding to His 148 of N. crassa CMLE; Arg 234, corresponding to Arg 196; Glu 250, corresponding to Glu 212; and Arg 302, corresponding to Arg 274). Fig. 1(b) shows the model of the PA4204 encoded protein (without the signal peptide) based on the structure of YbhE from E. coli aligned with the N. crassa CMLE structure. His 148, Arg 196, Glu 212 and Arg 274 corresponding to the active site of $N$. crassa CMLE are shown in cyan, while the corresponding residues in the $P$. aeruginosa enzyme are shown in green. The rest of the CMLE molecule is omitted for clarity, but aligned perfectly (protein backbones are aligned). The model shows clearly that the enzyme from $P$. aeruginosa has the same $\beta$ propeller fold as YbhE and the N. crassa CMLE (Kajander et al., 2002).

\section{Phenotypic effects resulting from the inactivation of PA4204 in P. aeruginosa}

To investigate the role of PA4204 in P. aeruginosa an unmarked deletion was generated in this gene using the pDM4 vector (see Methods). The P. aeruginosa PA4204 mutant showed a significantly extended lag phase when grown in LB (Fig. 2a, growth monitored in triplicate, see 
(a)

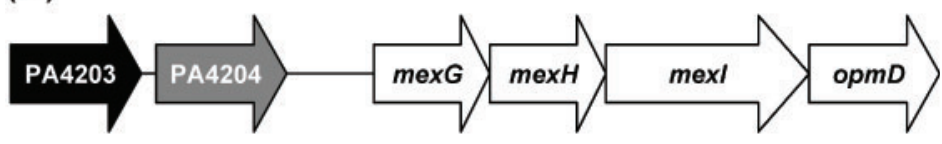

(b)

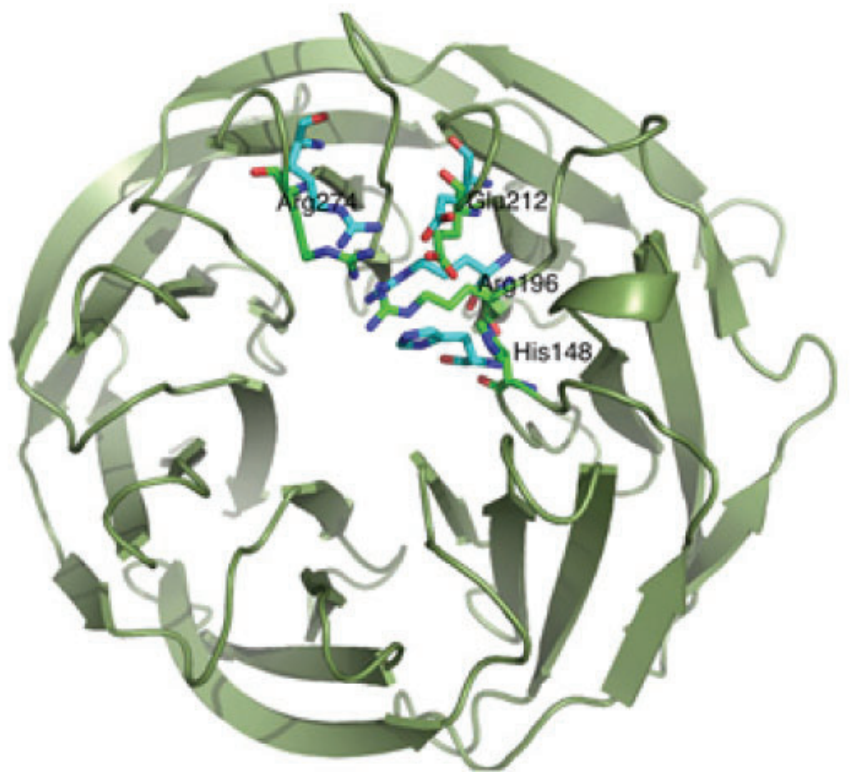

Fig. 1. (a) Genomic context of the PA4204 gene in $P$. aeruginosa PAO1. (b) Model of the PA4204 protein based on the crystal structure of $E$. coli YbhE phosphogluconolactonase and N. crassa CMLE. Residues in the active site of PA4204 are shown in green; those from $N$. crassa CMLE are shown in cyan. The numbering of the active site residues corresponds to the $N$. crassa CMLE (see text for details).
Methods), in relation to the parent, and formed very small colonies after 3 days of incubation at $37{ }^{\circ} \mathrm{C}$ (Fig. 2b). On plates, larger colonies appeared at a frequency of $10^{-4}$, suggesting the emergence of spontaneous compensatory mutation(s) (Fig. 2b). These spontaneous mutants or largecolony variants showed similar growth to that of the parent (Fig. 2a). Remarkably, the PA4204 deletion resulted in the almost complete loss of the blue-green pigment pyocyanin from the small colonies, whereas the large-colony variants could produce pyocyanin, albeit at lower levels compared with the wild-type (Fig. 3). Complementation of the smallcolony mutants with the PA4204 gene resulted in the restoration of wild-type pyocyanin levels (Fig. 3).

\section{Effect of the PA4204 mutation on QS signal molecule production}

The observation that the PA4204 small-colony mutant was unable to produce pyocyanin prompted us to look at the levels of QS signal molecules, since the production of this phenazine pigment is controlled by QS via the Rhl system and via the production of PQS and its precursor 2-heptyl4-quinolone (HHQ) (Gallagher et al., 2002; Dietrich et al., 2006; Price-Whelan et al., 2006; Fletcher et al., 2007; Diggle et al., 2007). As shown in Fig. 4(a), both types of PA4204 mutants showed decreased production of the $\mathrm{N}$-acylhomoserine lactones C4-HSL and 3-oxo-C12-HSL, as deter- mined by quantitative LC-MS analysis. AQ levels, however, were reduced dramatically in the cell-bound fraction as well as in the supernatant of the small-colony PA4204 mutant. Conversely, the levels of these molecules in the large-colony variant were the same or even higher than those in the wild-type PAO1 (Fig. 4b, upper panel corresponding to the cellular fraction, lower panel to the supernatant extracts).

\section{Structure-function analysis of the protein encoded by PA4204}

The existence of conserved residues in the active site of the carboxymuconate lactonizing enzyme CMLE and in the gene product of PA4204 (Fig. 1b) suggested that these two proteins may share a conserved active site. To investigate this, we mutagenized the His 184 residue from the $P$. aeruginosa protein, corresponding to His 148 in the CMLE active site, by either deleting it or changing it to an alanine. Fig. 3 shows that a mutation of this residue resulted in the inability of the gene to restore pyocyanin production in the PA4204 isogenic mutant. This shows clearly that the histidine residue predicted to be important for the activity of CMLEs is also important for the activity of the $P$. aeruginosa PA4204 protein. This effect was observed on LB, but was even more pronounced on Pseudomonas $\mathrm{P}$ agar (data not shown). 


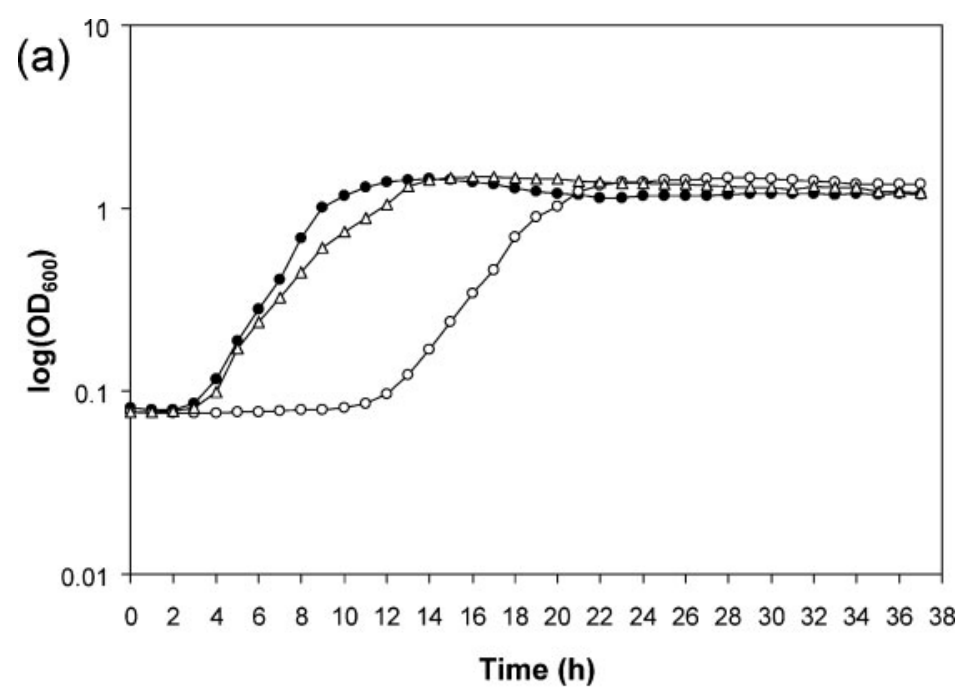

(b)

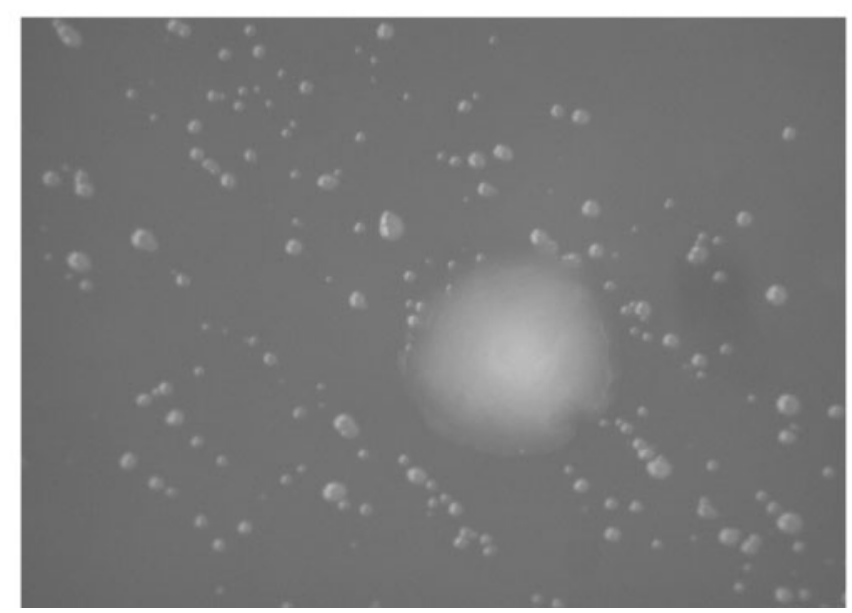

\begin{abstract}
Fig. 2. (a) Growth of wild-type $P$. aeruginosa (O), small-colony PA4204 mutant $(\bigcirc)$, and large-colony revertant $(\triangle)$ in LB medium. Growth was followed in three independent wells and the results considered valid only when the three curves were identical. (b) Appearance of a large-colony revertant of a PA4204 mutant surrounded by the original small-colony type. The large-colony pseudorevertant colony size is indistinguishable from that of the wild-type.
\end{abstract}

\section{Cloning, expression and purification of the PA4204 protein}

The complete ORF of PA4204 was cloned in the pET24 expression vector, which allows high levels of expression after IPTG induction as well as purification via a Cterminal His-tag. Fig. 5 shows the induction and purification of the PA4204 protein. After His-trap chromatography and elution of bound proteins with imidazole, two proteins were eluted (Fig. 5a), one with an apparent molecular mass of about $40 \mathrm{kDa}$, the other of $36-38 \mathrm{kDa}$. No other band or degradation product was observed. The larger protein was clearly less abundant when the proteins were extracted after $5 \mathrm{~h}$ of induction

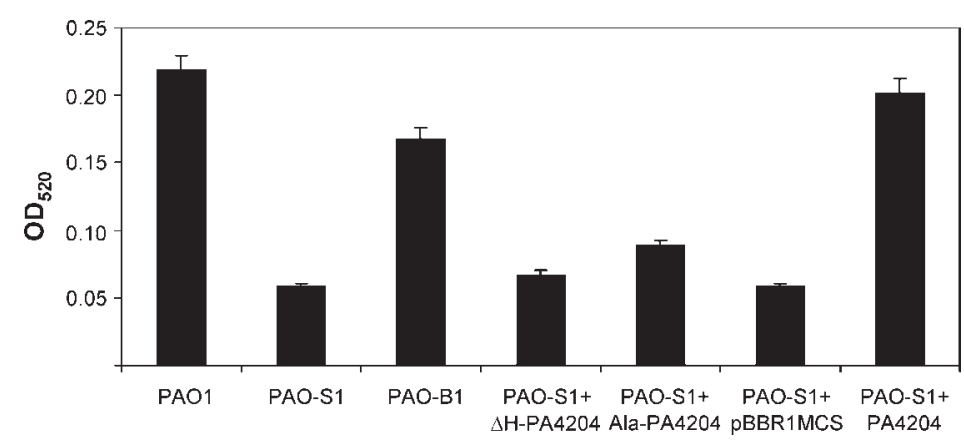

Fig. 3. Pyocyanin production on LB medium of wild-type (PAO1), PA4204 small-colony mutant (S1), PA4204 large-colony revertant (B1), PA4204 small-colony mutant complemented with PA4204 cloned in pBBR1MCS and lacking His 182, complemented with PA4204 with His 182 replaced by Ala, PA4204 mutant containing the empty vector pBBR1MCS, and PA4204 mutant complemented with the wild-type PA4204 gene. The results are the mean of three experiments; error bars show SD. 
(a)

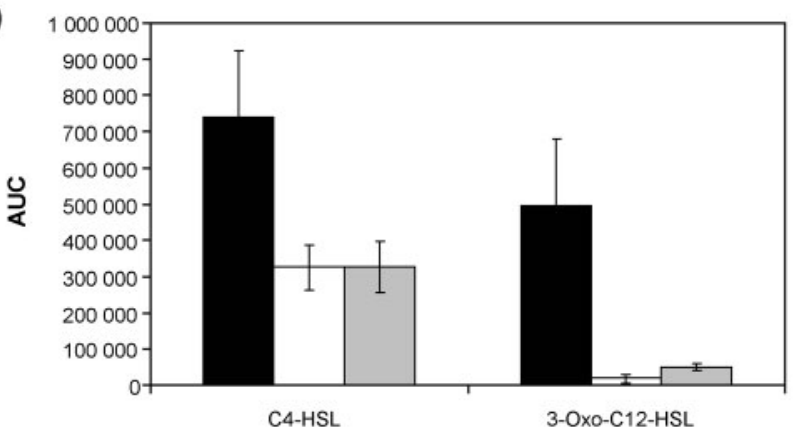

(b)
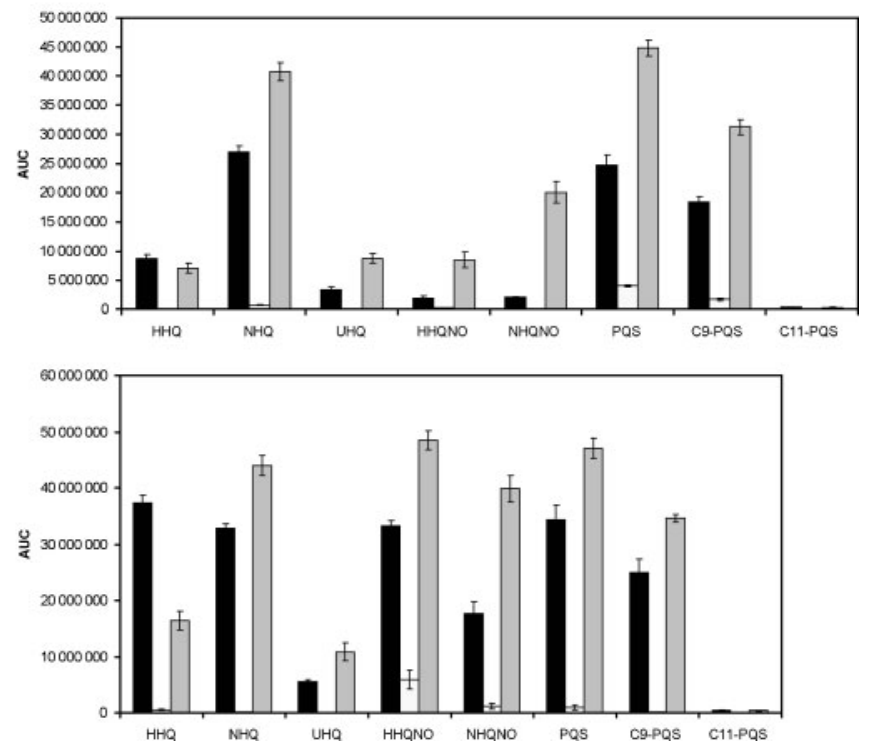

Fig. 4. (a) Detection by LC-MS of $N$-acylhomoserine lactones (C4-HSL and 3-oxo-C12$\mathrm{HSL}$ ) in supernatant extracts from wild-type PAO1 (black bars), PA4204 small-colony mutant (white bars), and PA4204 large-colony variant (grey bars). The values are the mean of three experiments from five separate extractions; error bars show SD. (b) Upper panel: detection by LC-MS of AQs in cellular extracts of wild-type (black bars), PA4204 small-colony mutant (white bars), and PA4204 large-colony variants (grey bars). HHQ, 2-heptyl-4-quinolone; NHQ, 2-nonyl-4-quinolone; UHQ, 2undecyl-4-quinolone; HHQNO, 2-heptyl-4hydroxyquinoline- $\mathrm{N}$-oxide; NHONO, 2-nonyl4-hydroxyquinoline- $\mathrm{N}$-oxide; POS, 2-heptyl-3hydroxy-4-quinolone; C9-PQS, 2-nonyl-3hydroxy-4-quinolone; C11-PQS, 2-undecyl3-hydroxy-4-quinolone. Lower panel: similar, but for extracellular extracts.

compared with overnight induction. Western blot analysis showed that both proteins were detected by an anti-His-tag $\mathrm{mAb}$ (results not shown). This result is consistent with the processing of the signal peptide of the pre-protein, suggesting a periplasmic localization, as predicted by the presence of a cleavable signal peptide.

\section{Lactonase activity of the PA4204 protein}

Since the PA4204 protein showed a high level of similarity to the lactonase of Pectobacterium (Erwinia) cyprepedii (Mochizuki, 2003, 2006), we examined the activity of the purified protein against the substrate (S)-5-oxo-2-tetrahydrofurancarboxylic acid (Fig. 5b). As shown in Fig. 5(b), the commercial substrate $(S)$-5-oxo-2-tetrahydrofurancarboxylic acid gives two peaks on HPLC (left panel) and these peaks disappear after incubation with the purified protein fraction (right panel). This result corresponds to what has been described by Mochizuki (2006). Analysis of the different peaks and of the purified substrate $[(S)-5$ oxo-2-tetrahydrofurancarboxylic acid] and product ( $L-\alpha-$ hydroxyglutaric acid) shows that the peak eluting early corresponds to L- $\alpha$-hydroxyglutaric acid $(m / z 147)$. Finally, Fig. 5(c) shows that the purified enzyme has a clear lactonase activity when D-glucono- $\delta$-lactone is used as substrate. When the enzyme was boiled for $10 \mathrm{~min}$ the opening of the gluconolactone occurred at the same rate as without enzyme (spontaneous decay). The enzyme was also partially sensitive to EDTA (Fig. 5c).

\section{Utilization of different carbon sources}

Growth was followed in minimal succinate medium containing a reduced amount of succinate $(2 \mathrm{mM})$ and in the presence of $20 \mathrm{mM}$ phenol, succinate, protocatechuate, cis,cis-muconate, catechol, glucose, fructose, glycerol, gluconate, 2-ketogluconate or mannitol. Growth was always lower for the mutant compared with the wild-type (results not shown), but in the case of gluconate, 2-ketogluconate and mannitol, almost no growth was observed for the PA4204 mutant (Fig. 6a, b, results shown for gluconate and mannitol). Interestingly, the large-colony pseudo-revertant could grow in these media (Fig. 6a, b). Complementation with the $\mathrm{pBBR}$ vector containing the wild-type PA4204 gene restored growth on gluconate, 2-ketogluconate, and mannitol (Fig. 6a, b), while the His-Ala substitution in PA4204 did not confer growth, again confirming the importance of this predicted active site residue (Fig. 6a, b). 

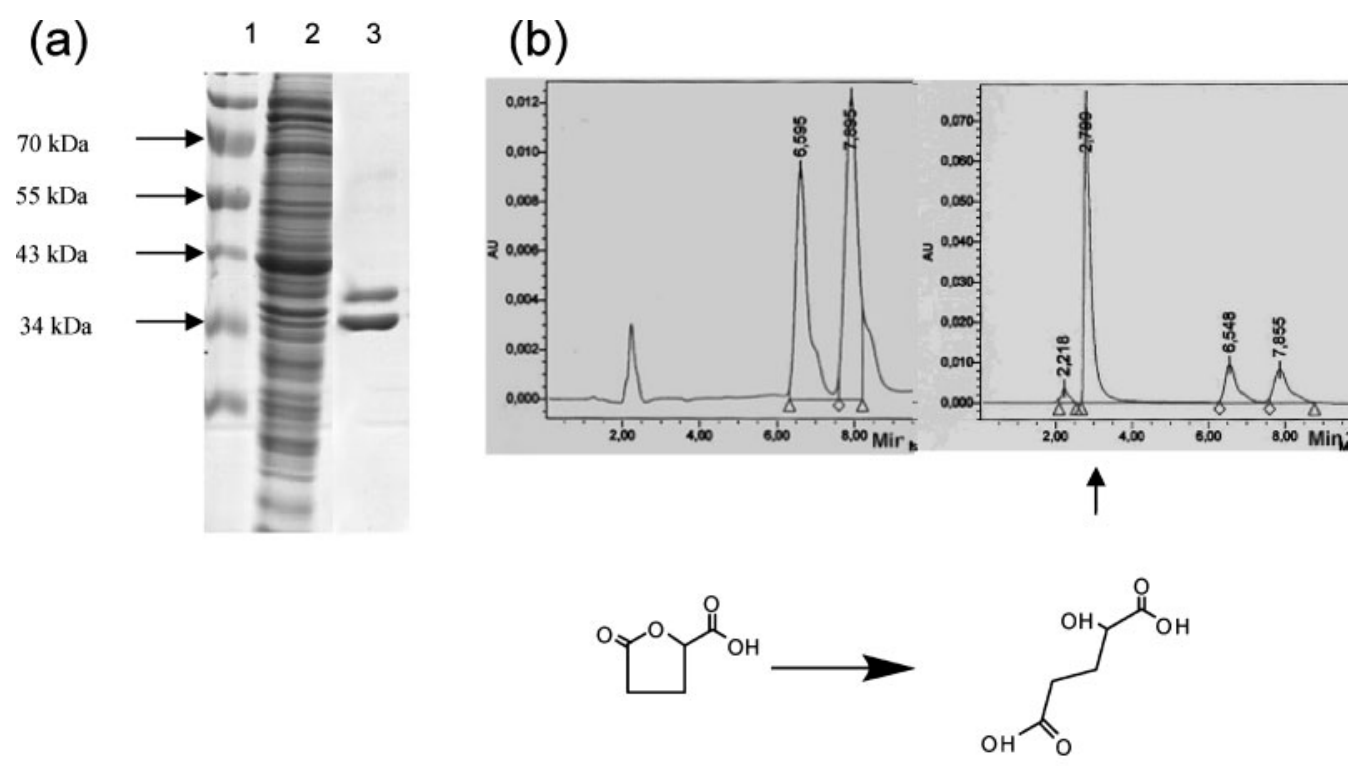

(S)-5-Oxo-2-tetrahydrofurancarboxylic acid

L- $\alpha$-Hydroxyglutaric acid

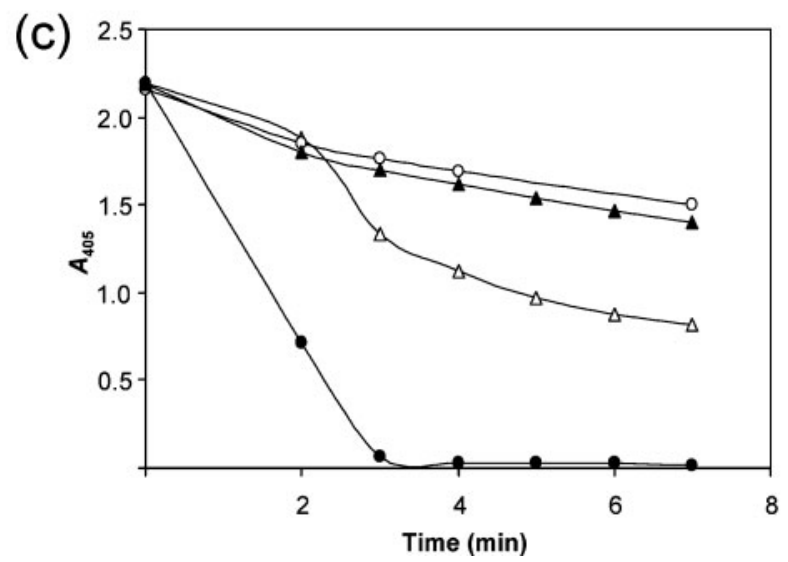

Fig. 5. Expression and purification of the PA4204 protein cloned in the pET24 vector. (a) SDS-PAGE gel (12\%) with overnight-induced crude extract of pET24 containing PA4204 (lane 2), and His-trap-bound protein fraction from overnightinduced crude extract (lane 3); lane 1, molecular mass markers. (b) HPLC separation of (S)-5-oxo-2-tetrahydrofurancarboxylic acid (left panel), and after addition of $16 \mu \mathrm{g}$ purified protein (right panel). Below is the reaction described by Mochizuki (2006) for the Pectobacterium (Erwinia) cypripedii homologue. (c) Gluconolactonase activity of the purified enzyme. The activity is measured as the drop in $A_{405}$ of the $\mathrm{pH}$ indicator $p$-nitrophenol due to the acidification caused by the opening of the lactone ring of D-glucono- $\delta$-lactone in the presence of $1.6 \mu \mathrm{g}$ purified enzyme $(\bullet)$ or the enzyme boiled for $10 \mathrm{~min}(\bigcirc)$. The rate of spontaneous hydrolysis is also shown $(\mathbf{\Delta})$ as well as the inhibition caused by adding EDTA (0.01 M final) to the reaction mix containing the enzyme $(\triangle)$.

\section{RT-PCR analysis of the phosphogluconolactonase gene (pgl)}

As mentioned in the Introduction, $P$. aeruginosa has a $p g l$ gene (PA3182) encoding a cytoplasmic phosphogluconolactonase. Because the product of PA4204 is a periplasmic gluconolactonase, we wanted to know whether the absence of this activity in the PA4204 mutant could affect the production of Pgl. As shown in Fig. 6(c), a clear reduction in the amount of cDNA was visible when the mRNA was extracted from the small-colony PA4204 mutant, while an increased expression of $p g l$ was apparent in the complemented strain and in the large-colony variant.

\section{DISCUSSION}

The PA4204 gene in P. aeruginosa is found upstream of the mexGHI-opmD operon, which encodes the components of an efflux pump known to have a close relationship with the 
(a)

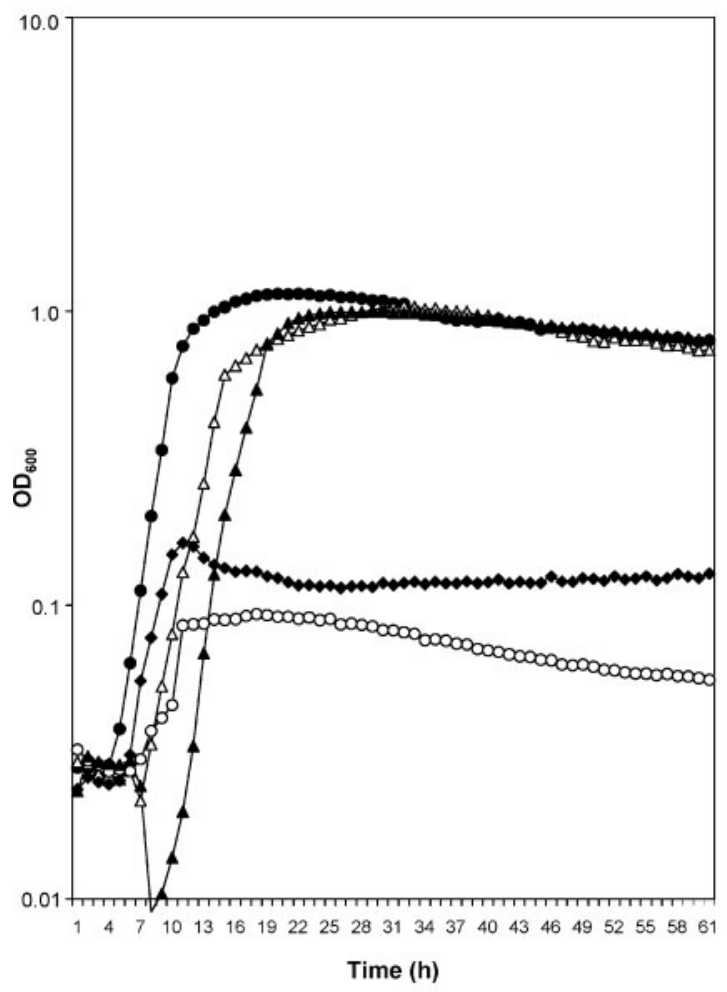

(c)

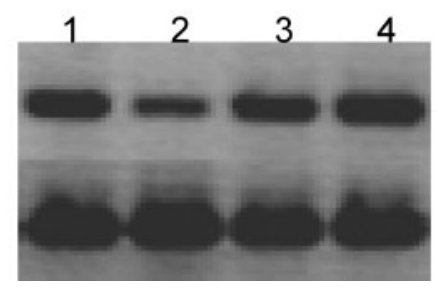

(b)

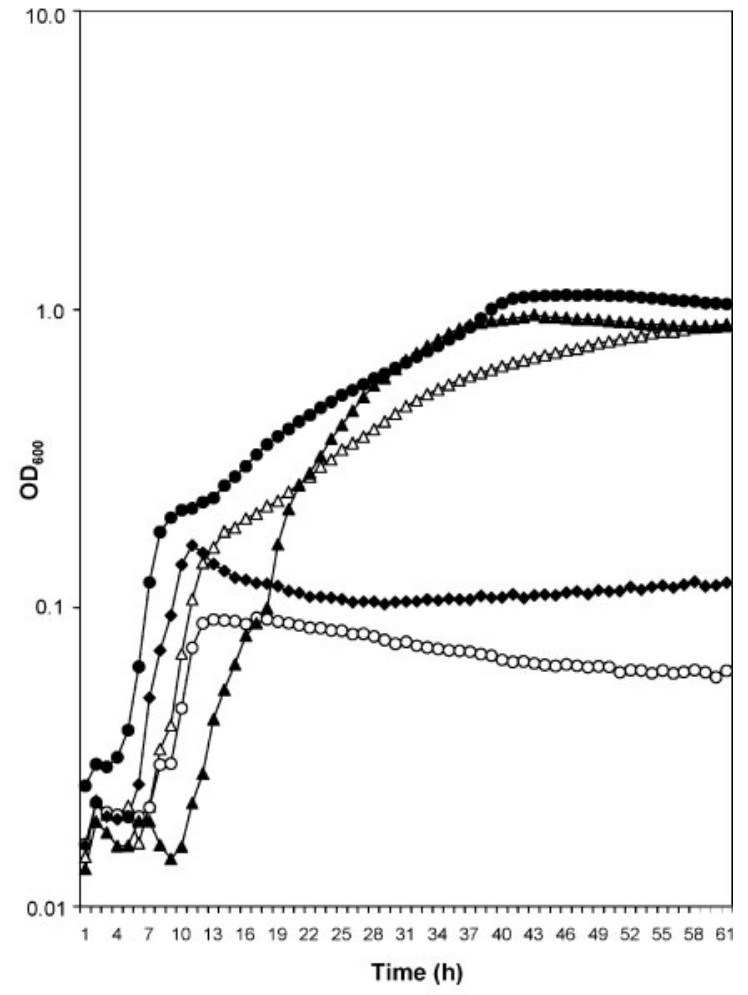

Fig. 6. Growth of wild-type P. aeruginosa (•), PA4204 mutant ( $\bigcirc)$, PA4204 pseudorevertant (A), PA4204 complemented with the wild-type gene $(\triangle)$, and PA4204 complemented with the His-Ala mutated gene $(\Delta)$ in the presence of gluconate (a) or mannitol (b). (c) RT-PCR analysis of the expression of the PA3182 gene (pgl) encoding the cytoplasmic Pgl. Lanes: 1, wildtype; 2, PA4204 mutant (small-colony); 3, complemented PA4204 mutant; 4, large-colony variant of the PA4204 mutant. The bottom row shows the amplification of the oprL gene encoding the peptidoglycan-associated lipoprotein (PAL).

QS circuitry in this bacterium (Aendekerk et al., 2002, 2005; Dietrich et al., 2006; Bredenbruch et al., 2006). Homologues of the PA4204 protein are present in the genomes of other fluorescent pseudomonads, such as $P$. syringae, but the mexGHI-opmD genes are found in $P$. aeruginosa alone. The genomic proximity to the pump genes prompted us to investigate the function of this gene and of the protein that it encodes. In this work, we show that the PA4204 mutant does not produce pyocyanin, which has been proposed recently to be a fourth signal molecule in P. aeruginosa (Dietrich et al., 2006). However, the effect of PA4204 on QS may be indirect and due to a pleiotropic effect on the physiology of the bacterium, since this gene has never been found to be regulated by QS signal molecules in the different genome-wide transcriptome analyses of the AHL- or PQS-mediated responses in $P$. aeruginosa (Schuster et al., 2003; Wagner et al., 2003; Hentzer et al., 2003; Juhas et al., 2004; Bredenbruch et al., 2006). The exact function of PA4204 cannot yet be predicted unequivocally, but we confirmed here that it has a gluconolactonase activity. Although the protein contains a COG2706 domain corresponding to a CMLE, it also bears similarity to PGLs. However, PGLs are normally cytoplasmic, while the product of PA4204 is probably localized in the periplasm, a fact that we could confirm, since the signal peptide of PA4204 is processed when the gene is expressed in E. coli (Fig. 5). The protein encoded by PA4204 also has the same enzymic activity as the predicted 
periplasmic enzyme described by Mochizuki (2003, 2006) in Pectobacterium (Erwinia) cypripedii 314B, with a lactonase activity for (S)-5-oxo-2-tetrahydrofurancarboxylic acid, which converts this molecule to $\mathrm{L}-\alpha$-hydroxyglutaric acid. The substrate of the Pectobacterium (Erwinia) cypripedii lactonase, (S)-5-oxo-2-tetrahydrofurancarboxylic acid, resembles 2-carboxy-2,5-dihydro-5-oxofuran-2-acetate, better known as $\gamma$-carboxymuconolactone, one of the intermediates in the protocatechuate degradation pathway and the substrate of CMLE. In P. aeruginosa, the CMLE involved in the protocatechuate pathway is $\mathrm{PcaB}$, which again is a cytoplasmic enzyme. There is, however, little similarity between $\mathrm{PcaB}$ and the PA4204 product. In fact, the putative PA4204-encoded CMLE is more closely related to the eukaryotic CMLEs represented by the N. crassa enzyme (Mazur et al., 1994). We also demonstrated that the enzyme has a clear gluconolactonase activity (Fig. 5c). An interesting observation is the absence of growth of the PA4204 mutant in minimal medium containing gluconate, 2-ketogluconate or mannitol. A $P$. aeruginosa pgl mutant (with defective cytoplasmic Pgl) has been described as failing to grow on mannitol and showing reduced growth on gluconate (Hager et al., 2000). Here, we could demonstrate a similar phenotype for our PA4204 mutant, except that growth on gluconate was almost abolished. Furthermore, a clear decrease in expression of $\mathrm{pgl} \mathrm{results} \mathrm{from} \mathrm{the} \mathrm{inactivation} \mathrm{of} \mathrm{PA4204,} \mathrm{suggesting} \mathrm{that}$ the lactonization of gluconate in the periplasm reduces the amount of gluconate that can enter the ED pathway. Recently, a membrane sensor protein has been described in $P$. aeruginosa, which is needed for biofilm formation, production of the siderophore pyoverdine, and growth on mannitol and gluconate (Attila et al., 2008). Interestingly, the PA4204 mutant also shows a strongly reduced capacity

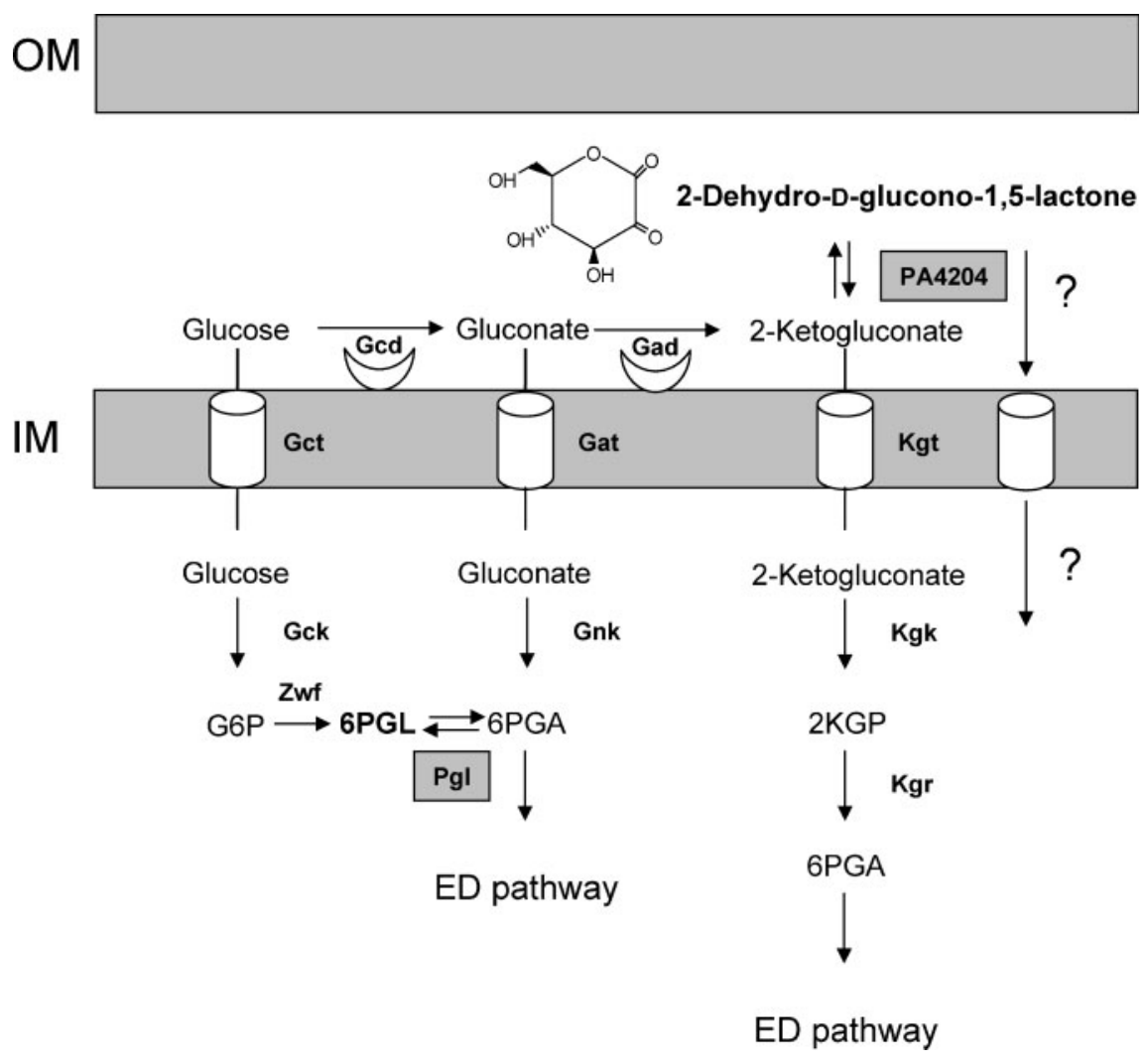

Fig. 7. The glucose pathway in $P$. aeruginosa and possible function of PA4204. In the periplasm, glucose is transported via the Gct transporter into the cytoplasm, where the Gck glucokinase phosphorylates it into glucose 6-phosphate (G6P). G6P is oxidized by the glucose phosphate dehydrogenase Zwf to give $\delta$-6-phosphogluconolactone (6GPL), which can isomerize into the toxic $\gamma$-6-phosphogluconolactone. The enzyme Pgl can convert the lactone into 6-phosphogluconate (6PGA), the central metabolite of the ED pathway. Glucose can be oxidized in the periplasm by the membrane-bound Gcd dehydrogenase to give gluconate, which can be transported into the cytoplasm via the Gat transporter or oxidized further via another dehydrogenase, Gad, into 2-ketogluconate, which is transported into the cytoplasm via Kgt. According to the KEGG prediction, 2-ketogluconate can convert spontaneously to 2-dehydro-D-glucono-1,5-lactone. The function of the PA4204 enzyme in the periplasm could be to convert this lactone back into 2-ketogluconate. It is not known whether 2-dehydro-D-glucono-1,5-lactone is also transported into the cytoplasm. 
to form biofilms (results not shown). We therefore propose a model that can explain the different phenotypic defects observed when PA4204 is inactivated (Fig. 7). The PA4204 enzyme is probably a periplasmic gluconolactonase active against either gluconolactone or a lactone compound (2dehydro-D-glucono-1,5-lactone) that originates spontaneously from 2-ketogluconate, which itself is the product of the oxidation of gluconate by the membrane-bound gluconate dehydrogenase encoded by gad (PA2265). In Pectobacterium (Erwinia) cypripedii, the gluconate dehydrogenase is a three-component enzyme comprising a small subunit, the Gad flavoprotein and a $c$-type cytochrome (Yum et al., 1997). In P. aeruginosa, the same genes (PA2264-PA2266) are found in the same order as in Pectobacterium (Erwinia) cypripedii (http://www.pseudomonas.com). The 2-ketogluconate molecule can isomerize spontaneously to form 2-dehydro-D-glucono-1,5-lactone (Kegg prediction). A possible function of the periplasmic PA4204 enzyme could be to convert this lactone (or gluconolactone) back into 2-ketogluconate (or gluconate), which can be transported to the cytoplasm. The fact that growth in the presence of glucose is not affected by the mutation of PA4204 is probably due to the fact that glucose can be transported to the cytoplasm, converted to glucose 6-phosphate and then to 6-phosphogluconate, and that the cytoplasmic Pgl suffices to ensure the hydrolysis of 6phosphogluconolactone, thereby fuelling the ED pathway (Fig. 7). We hypothesize that in the absence of PA4204, gluconolactone and/or 2-dehydro-D-glucono-1,5-lactone accumulate in the periplasm and that these products are toxic to the cell, in agreement with the house-cleaning function suggested by Galperin et al. (2006). Alternatively, the compound could exert its toxicity in the cytoplasm, if it is transported to this cellular compartment. The mechanism by which gluconolactone or 2-dehydro-D-glucono1,5-lactone inhibits the production of both AHLs and AQs is not clear, but both QS systems could be affected due to the perturbation in the general metabolism of the cell. Since the PA4204 periplasmic enzyme has a gluconolactonase activity, we propose to name this gene $p p g L$ (periplasmic gluconolactonase).

More research will be required to further characterize the PpgL enzyme activity towards different lactones, including the predicted biologically relevant substrate 2-dehydro-Dglucono-1,5-lactone (which is not available commercially and needs to be chemically synthesized).

\section{ACKNOWLEDGEMENTS}

This work was supported by research grants from the FWO Belgium (Fonds voor Wetenschappelijk Onderzoek Vlaanderen), and Biotechnology and Biological Sciences Research Council, UK (to P.W., M.C. and M.P.F.). S.T. had a fellowship from the Iranian Ministry of Science, Research and Technology and the Ferdowsi University of Mashad. Q. W. has a CSC scholarship (VUB-China). We would like to thank Stephan Heeb and Stephen Diggle for very valuable scientific discussions on this work, and Catherine Ortori for the LC-MS technical support.

\section{REFERENCES}

Aendekerk, S., Ghysels, B., Cornelis, P. \& Baysse, C. (2002). Characterization of a new efflux pump, MexGHI-OpmD, from Pseudomonas aeruginosa that confers resistance to vanadium. Microbiology 148, 2371-2381.

Aendekerk, S., Diggle, S. P., Song, Z., Hoiby, N., Cornelis, P., Williams, P. \& Cámara, M. (2005). The MexGHI-OpmD multidrug efflux pump controls growth, antibiotic susceptibility and virulence in Pseudomonas aeruginosa via 4-quinolone-dependent cell-to-cell communication. Microbiology 151, 1113-1125.

Altschul, S. F., Madden, T. L., Schaeffer, A. A., Zhang, J., Zhang, Z., Miller, W. \& Lipman, D. J. (1997). Gapped BLAST and PSI-BLAST: a new generation of protein database search programs. Nucleic Acids Res 25, 3389-3402.

Attila, C., Ueda, A. \& Wood, T. K. (2008). PA2663 (PpyR) increases biofilm formation in Pseudomonas aeruginosa PAO1 through the psl operon and stimulates virulence and quorum-sensing phenotypes. Appl Microbiol Biotechnol 78, 293-307.

Bredenbruch, F., Geffer, R., Nimtz, M., Buer, J. \& Haussler, S. (2006). The Pseudomonas aeruginosa quinolone signal (PQS) has an ironchelating activity. Environ Microbiol 8, 1318-1329.

Brünger, A. T., Adams, P. D., Clore, G. M., DeLano, W. L., Gros, P., Grosse-Kunstleve, R. W., Jiang, J. S., Kuszewski, J., Nilges, M. \& other authors (1998). Crystallography \& NMR system: new software suite for macromolecular structure determination. Acta Crystallogr D Biol Crystallogr 54, 905-921.

Dietrich, L. E., Price-Whelan, A., Petersen, A., Whiteley, M. \& Newman, D. K. (2006). The phenazine pyocyanin is a terminal signalling factor in the quorum sensing network of Pseudomonas aeruginosa. Mol Microbiol 61, 1308-1321.

Diggle, S. P., Cornelis, P., Williams, P. \& Cámara, M. (2006). 4Quinolone signaling in Pseudomonas aeruginosa: old molecules, new perspectives. Int J Med Microbiol 296, 83-91.

Diggle, S. P., Matthijs, S., Wright, V. J., Fletcher, M. P., Chhabra, S. R., Lamont, I. L., Kong, X., Hider, R. C., Cornelis, P. \& other authors (2007). The Pseudomonas aeruginosa 4-quinolone signal molecules HHQ and PQS play multifunctional roles in quorum sensing and iron entrapment. Chem Biol 14, 87-96.

Fletcher, M. P., Diggle, S. P., Cámara, M. \& Williams, P. (2007). Biosensor-based assays for PQS, HHQ and related 2-alkyl-4quinolone quorum sensing signal molecules. Nat Protoc 2, 1254-1262.

Forman, S., Bobrov, A. G., Krillina, O., Craig, S. K., Abney, J., Fetherston, J. D. \& Perry, R. D. (2006). Identification of critical amino acid residues in the plague biofilm Hms proteins. Microbiology 152, 3399-3410.

Gallagher, L. A., McKnight, S. L., Kuznetsova, M. S., Pesci, E. C. \& Manoil, C. (2002). Functions required for extracellular quinolone signaling by Pseudomonas aeruginosa. J Bacteriol 184, 6472-6480.

Galperin, M. Y., Moroz, O. V., Wilson, K. S. \& Murzin, A. G. (2006). House cleaning, a part of good housekeeping. Mol Microbiol 59, 5-19.

Goldberg, J. B. (2000). Pseudomonas: global bacteria. Trends Microbiol 8, 55-57.

Hager, P. W., Calfee, M. W. \& Phibbs, P. V. (2000). The Pseudomonas aeruginosa $\operatorname{dev} B / S O L$ homolog, $p g l$, is a member of the hex regulon and encodes 6-phosphogluconolactonase. J Bacteriol 182, 3934-3941.

Hanahan, D. (1983). Studies on transformation of Escherichia coli with plasmids. J Mol Biol 166, 557-580.

Hentzer, M., Riedel, K., Rasmussen, T. B., Heydorn, A., Andersen, J. B., Parsek, M. R., Rice, S. A., Eberl, L., Molin, S. \& other authors (2002). Inhibition of quorum sensing in Pseudomonas aeruginosa 
biofilm bacteria by a halogenated furanone compound. Microbiology 148, 87-102.

Hentzer, M., Wu, H., Andersen, J. B., Riedel, K., Rasmussen, T. B., Bagge, N., Kumar, N., Schembri, M. A., Song, Z. \& other authors (2003). Attenuation of Pseudomonas aeruginosa virulence by quorum sensing inhibitors. EMBO J 22, 3803-3815.

Hucho, F. \& Wallenfels, K. (1972). Glucono- $\delta$-lactonase from Escherichia coli. Biochim Biophys Acta 276, 176-179.

Jones, T. A., Zou, J. Y., Cowan, S. W. \& Kjeldgaard, M. (1991). Improved methods for the building of protein models in electron density maps and the location of errors in these models. Acta Crystallogr A 47, 110-119.

Juhas, M., Wiehlmann, L., Huber, B., Jordan, D., Lauber, J., Salunkhe, P., Limpert, A. S., von Götz, F., Steinmetz, I. \& other authors (2004). Global regulation of quorum sensing and virulence by VqsR in Pseudomonas aeruginosa. Microbiology 150, 831-841.

Kajander, T., Merckel, M. C., Thompson, A., Deacon, A. M., Mazur, P., Kozarich, J. W. \& Goldman, A. (2002). The structure of Neurospora crassa 3-carboxy-cis,cis-muconate lactonizing enzyme, a $\beta$ propeller cycloisomerase. Structure 10, 483-492.

King, E. O., Ward, M. K. \& Raney, D. E. (1954). Two simple media for the demonstration of pyocyanin and fluorescein. J Lab Clin Med 44, 301-307.

Kovach, M. E., Phillips, W., Elzer, P. H., Roop, R. M. \& Peterson, K. M. (1994). pBBR1MCS: a broad-host-range cloning vector. Biotechniques 16, 800-801.

Kupor, S. R. \& Fraenkel, D. G. (1969). 6-Phosphogluconolactonase mutants of Escherichia coli and a maltose blue gene. J Bacteriol 100, 1296-1301.

Lassmann, T. \& Sonnhammer, E. L. (2006). Kalign, Kalignvu and Mumsa: web servers for multiple sequence alignment. Nucleic Acids Res 34, W596-W599.

Lewenza, S., Gardy, G. L., Brinkman, F. S. \& Hancock, R. E. (2005). Genome-wide identification of Pseudomonas aeruginosa exported proteins using a consensus computational strategy combined with a laboratory-based PhoA fusion screen. Genome Res 15, 321-329.

Mavrodi, D. V., Bonsall, R. F., Delaney, S. M., Soule, M. J., Phillips, G. \& Thomashow, L. S. (2001). Functional analysis of genes for biosynthesis of pyocyanin and phenazine-1-carboxamide from Pseudomonas aeruginosa PAO1. J Bacteriol 183, 6454-6465.

Mazur, P., Henzel, W. J., Mattoo, S. \& Kozarich, W. J. (1994). 3Carboxy-cis,cis-muconate lactonizing enzyme from Neurospora crassa: an alternate cycloisomerase motif. J Bacteriol 176, 1718-1728.

McClean, K. H., Winson, M. K., Fish, L., Taylor, A., Chhabra, S. R., Cámara, M., Daykin, M., Lamb, J. H., Swift, S. \& other authors (1997). Quorum sensing and Chromobacterium violaceum: exploitation of violacein production and inhibition for the detection of $\mathrm{N}$ acylhomoserine lactones. Microbiology 143, 3703-3711.

Meyer, J. M. \& Abdallah, M. A. (1978). The fluorescent pigment of Pseudomonas fluorescens: biosynthesis, purification and physicochemical properties. J Gen Microbiol 107, 319-328.

Miclet, E., Stoven, V., Michels, P. A., Opperdoes, F. R., Lallemand, J. Y. \& Duffieux, F. (2001). NMR spectroscopic analysis of the first two steps of the pentose-phosphate pathway elucidates the role of 6phosphogluconolactonase. J Biol Chem 276, 34840-34846.
Milton, D. L., O'Toole, R., Horstedt, P. \& Wolf-Watz, H. (1996). Flagellin A is essential for the virulence of Vibrio anguillarum. J Bacteriol 178, 1310-1319.

Mochizuki, K. (2001). Purification and characterization of a lactonase from Burkholderia sp. R-711, that hydrolyzes $(R)$-5-oxo-2-tetrahydrofurancarboxylic acid. Arch Microbiol 175, 430-434.

Mochizuki, K. (2003). Purification and characterization of a lactonase from Erwinia cyprepedii 314B that hydolyses (S)-5-oxo-2-tetrahydrofurancarboxylic acid. Arch Microbiol 180, 490-493.

Mochizuki, K. (2006). Cloning, sequencing, and heterologous expression of an Erwinia cypripedii 314B lactonase specific for $\mathrm{L}-\alpha-$ hydroglutaric acid $\gamma$-lactone. Appl Microbiol Biotechnol 71, 863-869.

Ortori, C. A., Atkinson, S., Chhabra, S. R., Cámara, M., Williams, P. \& Barrett, D. A. (2007). Comprehensive profiling of $\mathrm{N}$-acylhomoserine lactones produced by Yersinia pseudotuberculosis using liquid chromatography coupled to hybrid quadrupole-linear ion trap mass spectrometry. Anal Bioanal Chem 387, 497-511.

Price-Whelan, A., Dietrich, L. A. \& Newman, D. K. (2006). Rethinking 'secondary' metabolism: physiological roles for phenazine antibiotics. Nat Chem Biol 2, 71-78.

Rychlewski, L., Jaroszewski, L., Li, W. \& Godzik, A. (2000). Comparison of sequence profiles. Strategies for structural predictions using sequence information. Protein Sci 9, 232-241.

Sambrook, J., Fritsch, E. F. \& Maniatis, T. (1989). Molecular Cloning: a Laboratory Manual, 2nd edn. Cold Spring Harbor, NY: Cold Spring Harbor Laboratory.

Schuster, M., Lostroh, C. P., Ogi, T. \& Greenberg, E. P. (2003). Identification, timing, and signal specificity of Pseudomonas aeruginosa quorum-controlled genes: a transcriptome analysis. J Bacteriol 185, 2066-2079.

Simon, R., Priefer, U. \& Pühler, A. (1983). A broad host-range mobilization system for in vivo genetic engineering: transposon mutagenesis in Gram-negative bacteria. Bio/Technology 1, 784-791.

Thomason, L. C., Court, D. L., Datta, A. R., Khanna, R. \& Rosner, J. L. (2004). Identification of the Escherichia coli K-12 ybhE gene as $p g l$, encoding 6-phosphogluconolactonase. J Bacteriol 186, 8248-8253.

Thompson, J. D., Gibson, T. J., Plewniak, F., Jeanmougin, F. \& Higgins, D. G. (1997). The CLUSTAL_X windows interface: flexible strategies for multiple sequence alignment aided by quality analysis tools. Nucleic Acids Res 25, 4876-4882.

Wagner, V. E., Bushnell, D., Passador, L., Brooks, A. I. \& Iglewski, B. H. (2003). Microarray analysis of Pseudomonas aeruginosa quorumsensing regulons: effects of growth phase and environment. J Bacteriol 185, 2080-2095.

Yum, D. Y., Lee, Y. P. \& Pan, J. G. (1997). Cloning and expression of a gene cluster encoding three subunits of membrane-bound gluconate dehydrogenase from Erwinia cypripedii ATCC 29267 in Escherichia coli. J Bacteriol 179, 6566-6572.

Zimenkov, D., Gulevich, A., Skorokhodova, A., Biriukova, I., Kozlov, Y. \& Mashko, S. (2005). Escherichia coli ORF $y b h E$ is $p g l$ gene encoding 6-phosphogluconolactonase (EC 3.1.1.31) that has no homology with known 6PGLs from other organisms. FEMS Microbiol Lett 244, 275-280.

Edited by: W. Bitter 